\title{
Comparison of the clinical and economic outcomes between open and minimally invasive appendectomy and colectomy: evidence from a large commercial payer database
}

\author{
Terrence M. Fullum · Joseph A. Ladapo • \\ Bijan J. Borah · Candace L. Gunnarsson
}

Received: 10 April 2009/Accepted: 27 July 2009/Published online: 3 September 2009

(c) The Author(s) 2009. This article is published with open access at Springerlink.com

\begin{abstract}
Background Appendectomy and colectomy are commonly performed surgical procedures. Despite evidence demonstrating advantages with the minimally invasive surgical (MIS) approach, open procedures occur with greater prevalence. Therefore, there is still controversy as to whether the MIS approach is safer or more cost effective.

Methods A retrospective analysis was performed using a large commercial payer database. The data included information on 7,532 appendectomies and 2,745 colectomies. Data on the distribution of patient demographic and comorbidity characteristics associated with the MIS and open approaches were reviewed. The corresponding complication rates and expenditures were analyzed. Summary statistics were compared using chi-square tests, and generalized linear models were constructed to estimate expenditures while controlling for patient characteristics.

Results The patients undergoing MIS and open colectomy showed no significant variations in age distribution or marginal age differences for appendectomy. Significantly
\end{abstract}

\section{T. M. Fullum}

Howard University College of Medicine, Washington, DC, USA

J. A. Ladapo

Beth Israel Deaconess Medical Center and Harvard Medical

School, Boston, MA, USA

B. J. Borah

i3 Innovus, Eden Prairie, MN, USA

C. L. Gunnarsson ( $₫)$

$S^{2}$ Statistical Solutions, Inc, 3276 East Sharon Road,

Cincinnati, OH 45241, USA

e-mail: candaceg@s2stats.com more patients experienced an infection postoperatively, and procedure-specific complications were more common in the open group for both procedures $(P<0.05)$. The postsurgical hospital stay was longer for the patients treated using the open techniques, differing an average of half a day for appendectomies and significantly more (4 days) for colectomy $(P<0.05)$. Readmission rates differed little between the two approaches. Procedures performed through an MIS approach were associated with lower expenditures than for the open technique, with differences ranging from $\$ 700$ for appendectomy patients $(P<0.05)$ to $\$ 15,200$ for colectomy patients $(P<0.05)$.

Conclusions Minimally invasive appendectomy and colectomy were associated with lower infection rates, fewer complications, shorter hospital stays, and lower expenditures than open surgery.

Keywords Abdominal - Minimally invasive . Economic outcomes - Appendectomy - Colectomy · Minimally invasive surgery (MIS) $\cdot$ Open procedure

Minimally invasive surgery (MIS) as an option for a variety of abdominal surgical procedures has grown increasingly common in recent years [1-11]. The general motivations for choosing MIS approaches have remained stable despite the wide variability in anatomic sites and procedure indications. Advocates argue that MIS techniques are more likely to reduce intraoperative blood loss, decrease pain, and shorten postsurgical convalescence [12, 13]. These benefits have been shown to translate into improved health-related quality of life for patients, and in some cases, reduction in health care expenditures [14-17]. However, even when evidence of MIS benefits is strong, as is the case for some surgeries, researchers have found that 
surgeon preference and resident training convention are frequently the most powerful predictors when the choice is made between MIS and the conventional (open) approach [18].

The results of randomized controlled clinical trials comparing open surgeries with their minimally invasive equivalents vary widely by trial design, surgeon experience, and MIS approach. This variability has fostered a reluctance of surgeons to accept the advantages of the minimally invasive approaches over conventional open techniques. Observational studies afford a complementary approach to randomized controlled trials in determining the potential benefits (and associated significance) of MIS versus open surgeries. Although randomized controlled trials are considered the "gold standard" for assessing safety and efficacy, observational studies offer several potential advantages, including the ability to assess multiple risk factors associated with a very large population base. For instance, the current study uses a database containing more than 14 million unique admissions. Such a large population often is more representative of the patients undergoing these surgeries, making the results obtained from observational studies more generalizable in terms of clinical and economic outcomes.

The decision to perform MIS instead of open surgery may have significant health policy implications. Where evidence supports improved health outcomes and shorter convalescence for patients, MIS approaches are likely to improve health-related quality of life. Insurers and hospital administrators also may exert preferences regarding hospital length of stay because this factor influences prospective payments and hospital operating margins.

Appendectomy and colectomy provide the opportunity to study outcomes from surgical decisions made in vastly different situations and with diverse patient considerations. Appendectomy often is an emergency procedure performed for otherwise healthy adults. The choice of surgical method is made quickly (vs. days or weeks), and the surgery often is performed using the MIS approach. Colectomy, on the other hand, usually is a planned procedure performed for older individuals who often have additional health concerns. The choice of surgical approach is made after many aspects of the patient's history and clinical status have been considered, and the surgery is more likely to be performed using open techniques $[7,10,11]$. Thus, appendectomy and colectomy afford the opportunity to compare and contrast MIS and open surgical outcomes from decisions made under differing circumstances.

The following analysis focuses on two commonly performed surgical procedures, appendectomy and colectomy, and the selected clinical and utilization outcomes associated with each.

\section{Materials and methods}

\section{Database description}

A retrospective analysis was performed using medical and pharmacy claims data and enrollment information from a large, fee-for-service U.S.-managed health care insurer. In 2005, the database contained more than 14 million individuals with both medical and pharmacy coverage. Physicians, facilities, and pharmacies submitted claims to the health plan insurer for payment covering services or prescription medications provided. For reimbursement purposes, the health plan requires service providers to include complete and accurate diagnosis and procedure information on medical claims submitted for payment. All study data used to perform this analysis were de-identified and accessed using protocols compliant with the Health Insurance Portability and Accountability Act (HIPAA), and no identifiable protected health information was extracted for the study.

\section{Inclusion criteria}

The two evaluated surgeries were appendectomy and colectomy. The inclusion criteria required that patients (1) had undergone one of these two surgeries between July 1, 2005 and June 30, 2006 and (2) were continuously enrolled in the health plan during this period as well as the 6 months before and after the date of their procedure. Patients were not excluded for surgeries performed for malignant conditions, an indication commonly observed in colectomy.

Open abdominal and MIS procedures were recorded according to the American Medical Association's Current Procedural Terminology (CPT) codes. Specifically, open abdominal colectomies include procedures with the CPT codes 44140, 44143, 44145, and 44146, whereas the CPT codes for laparoscopic (MIS) colectomies are 44204, 44206, 44207, and 44208. Similarly, the open abdominal appendectomy CPT codes are 44950 and 44955, whereas the CPT code for laparoscopic (MIS) appendectomy is 44970.

\section{Charlson Comorbidity Index}

The validity of the conclusions drawn from data obtained from large administrative databases mandates that the variable disease severity and the variety of comorbid illnesses be accounted for in the analysis. This was especially important for the current study because colectomy is more frequently performed in abdominal surgery as a part of the treatment for cancer, whereas appendectomy is more likely to be accomplished using laparoscopic methods for otherwise healthy individuals. 
The Charlson Comorbidity Index (CCI), tailored for use with medical records, is based on the International Classification of Diseases (ICD-9-CM) diagnosis and procedure codes found in administrative databases. The CCI predicts the 1-year mortality rate for a patient with a range of comorbid conditions ( 22 conditions). Each comorbid condition is assigned a score of $1,2,3$, or 6 depending on the mortality risk associated with this condition. The scores are summed and given a total score predicting mortality [19].

The CCI was tested for associations with dichotomous outcome measures such as complications from various comorbid conditions including cancer, mortality, and blood transfusion [20]. We also accounted for disease severity by modeling procedure-related expenditures incurred before the index procedure. This incorporated procedures and medical care related to the diagnosis and management of the patient before surgery.

Patient characteristics and clinical and economic outcomes

Data on the following patient characteristics were extracted: patient age, geographic residence, whether a patient's surgeon was a general surgeon or belonged to another specialty, and comorbidity severity using the CCI. Patient outcomes of interest, assessed over a 6-month follow-up period after the surgery, included both intra- and postoperative complications. Specifically, these outcomes consisted of overall infection rate, infection type, length of antibiotic use, number of major and minor bleeding episodes, and procedure-specific complication rates. Data on the length of hospital stay and rates of readmission also were collected. The economic variables included insurer and patient payment totals, cost capture of the surgical procedure, and expenditures related to follow-up office visits, emergency room visits, and hospitalizations.

The initial data capture included additional procedures for the abdomen. Patients were considered to have experienced a postsurgical infection if a claim was made for any of the following diagnoses: pulmonary infection, intraabdominal abscess or suppurative peritonitis, rectal abscess, retroperitoneal infection, infection of colostomy or enterostomy, urinary tract infection, breast abscess, pelvic organ infection, cellulites and skin abscess, local skin infection, acute lymphadenitis, sepsis, posttraumatic wound infection, or infection as a complication of care. Patients also were considered to have experienced a postsurgical infection if antibiotics were initiated within 3 days after surgery.

Patients were considered to have a diagnosis of bleeding if they had an ICD-9 code consistent with pathologic bleeding (Appendix) and fulfilled any one of the following criteria: history of a procedure-specific complication, an ICD-9 code consistent with a procedure used to control bleeding, or an ICD-9 code for blood transfusion with at least 2 units of packed red blood cells. Procedure-specific complications were defined for a period of 30 days after the surgery and included diagnoses of complications associated with the performance of the procedure as well as any diagnoses listed in the Appendix.

In this economic analysis, total expenditures for health care use directly associated with a patient's surgery were estimated. These expenditures comprised insurer and patient payments including the cost of the surgical procedure and all of the clinical events previously described. Also included were expenditures related to follow-up office visits, emergency room visits, and hospitalizations. Because the dates of these services were between 2005 and 2006, all expenditures were converted to 2006 U.S. dollars using the consumer price index (CPI).

Statistical analysis

Bivariate comparisons between MIS and open abdominal procedures were made using $t$ tests for continuous variables and chi-square tests for proportions. To model the expenditure for an episode of care, we used a generalized linear modeling (GLM) framework constructed using a gamma distribution and logarithmic link function [21, 22]. The reason for this approach is that expenditures are typically right-skewed. To address this issue, we estimated GLM gamma models. Findings have shown these models to be more efficient than alternative approaches such as semi-log models [21, 23]. The regression equation was used to estimate the effect of MIS and open abdominal surgery on health care expenditures separately for inpatient and outpatient procedures while controlling for observed covariates including an indicator for surgical approach, patient age, CCI, geographic region, and physician specialty. The predicted differences in expenditures between minimally invasive and open procedures then were bootstrapped (a general purpose approach to estimation) with 200 replications to estimate standard errors and confidence intervals [24].

The same GLM approach was adopted to estimate the duration of a care episode and the length of inpatient stay. Logistic regression was used to assess the probability of admission or readmission at days 30 and 60 after the surgery.

\section{Results}

Appendectomy

Between 1 July 2005 and 30 June 2006, the database identified 10,277 patients who met the study's inclusion 
criteria. Appendectomies were performed using predominantly an MIS approach. Of the 7,532 patients who underwent appendectomies, 5,304 (70\%) had MIS surgery and 2,228 (30\%) had open abdominal surgery (Table 1).

Age was divided into four strata: 0-17 years, 1834 years, 35-64 years, and 65 years or older. Although significant age differences were observed among the patients undergoing appendectomy, the overall pattern was ambiguous. Approximately 18 and $34 \%$ of the patients who underwent MIS appendectomy fell into the 0- to 17-year and 18- to 34-year strata, respectively. Similarly, approximately 24 and $28 \%$ of the patients who underwent open appendectomy fell into the 0- to 17-year and 18- to 34-year strata, respectively ( $P<0.05$ for both).

Table 2 reports postprocedural complications including infection rates, duration of associated antibiotic use, minor and major bleeding episodes, and procedure-specific complication rates. Significantly more appendectomy patients treated with open abdominal surgery experienced an infection postoperatively $(P<0.05)$. However, these significant differences in infection rates between MIS and open surgery were not reflected in days of antibiotics use. Significantly more incidences of minor and major bleeds occurred after appendectomies performed with open surgery $(P<0.05)$. Furthermore, procedure-specific complications were significantly more common for patients treated with an open approach $(P<0.05)$.

The sites of postprocedure infections by MIS versus open surgery are shown in Table 3. Intraabdominal, pulmonary, urinary, and skin infections were the most frequent for both MIS and open procedures. Infections were significantly more frequent $(P<0.05)$ for appendectomies performed using open versus MIS techniques.

The predicted length of hospital stay using GLM models and the unadjusted number of readmission/admissions for MIS and open procedures are shown in Table 4. These models were adjusted for surgical approach (MIS vs. open procedure), patient age, baseline CCI, geographic region, physician specialty, and whether the procedure was conducted in an inpatient or outpatient setting. The postsurgical length of stay was consistently longer for patients treated using conventional open surgical techniques, with an average difference of about a half day for appendectomy patients $(P<0.05)$. Readmissions rates generally differed little between the MIS and open approaches.

Expenditures and duration of care are shown in Table 5. Whereas duration of care did not vary for appendectomy

Table 1 Number of patients per procedure for minimally invasive surgery (MIS) versus open surgery ${ }^{\mathrm{a}}$

\begin{tabular}{|c|c|c|c|c|c|c|c|c|}
\hline & $n(\%)$ & Mean age & $\begin{array}{l}0-17 \text { years } \\
n(\%)\end{array}$ & $\begin{array}{l}18-34 \text { years } \\
n(\%)\end{array}$ & $\begin{array}{l}35-64 \text { years } \\
n(\%)\end{array}$ & $\begin{array}{l}65+\text { years } \\
n(\%)\end{array}$ & $\begin{array}{l}\text { Male/female } \\
n(\%)\end{array}$ & CCI \\
\hline \multicolumn{9}{|c|}{ Colectomy } \\
\hline MIS & $842(31)$ & $54.7 \pm 11.9$ & $2(0.2)$ & $40(4.8)$ & $648(77.0)$ & $152(18.1)$ & $435 / 407(51.7 / 48.3)$ & $1.1 \pm 1.6^{\mathrm{a}}$ \\
\hline Open & $1,903(69)$ & $55.4 \pm 12.8$ & $9(0.5)$ & $78(4.1)$ & $1,463(76.9)$ & $353(18.6)$ & $1,016 / 887(53.4 / 48.3)$ & $1.8 \pm 2.1^{\mathrm{a}}$ \\
\hline \multicolumn{9}{|c|}{ Appendectomy } \\
\hline MIS & $5,304(70)$ & $33.9 \pm 15.4$ & $949(17.9)^{\mathrm{a}}$ & $1,820(34.3)^{\mathrm{a}}$ & $2,436(45.9)^{\mathrm{a}}$ & $99(1.9)^{\mathrm{a}}$ & $2,664 / 2,640(50.2 / 49.8)$ & $0.2 \pm 0.6^{\mathrm{a}}$ \\
\hline Open & $2,228(30)$ & $33.5 \pm 17.2$ & $541(24.3)^{\mathrm{a}}$ & $625(28.1)^{\mathrm{a}}$ & $1,005(45.1)^{\mathrm{a}}$ & $57(2.6)^{\mathrm{a}}$ & $1,155 / 1,073(51.8 / 48.2)^{\mathrm{a}}$ & $0.3 \pm 0.9^{\mathrm{a}}$ \\
\hline
\end{tabular}

CCI Charlson Comorbidity Index, MIS minimally invasive surgery

${ }^{a} P<0.05$ MIS vs. open surgery

Table 2 Postprocedure complications for minimally invasive surgery (MIS) versus open surgery by procedure

\begin{tabular}{|c|c|c|c|c|c|c|}
\hline & Total & $\begin{array}{l}\text { Any infection } \\
n(\%)\end{array}$ & Days of antibiotic/patient & $\begin{array}{l}\text { Minor bleed } \\
n(\%)\end{array}$ & $\begin{array}{l}\text { Major bleed } \\
n(\%)\end{array}$ & $\begin{array}{l}\text { Procedure-specific } \\
\text { complication rate }^{\mathrm{a}}\end{array}$ \\
\hline \multicolumn{7}{|c|}{ Colectomy } \\
\hline MIS & 842 & $203(24)^{\mathrm{b}}$ & $12.23 \pm 17.81$ & $141(17)^{\mathrm{b}}$ & $34(4)^{\mathrm{b}}$ & $5.93 \pm 11.82^{b}$ \\
\hline Open & 1,903 & $728(38)^{\mathrm{b}}$ & $16.46 \pm 19.66$ & $443(23)^{\mathrm{b}}$ & $187(10)^{\mathrm{b}}$ & $8.56 \pm 12.40^{\mathrm{b}}$ \\
\hline \multicolumn{7}{|c|}{ Appendectomy } \\
\hline MIS & 5,304 & $863(16)^{\mathrm{b}}$ & $10.84 \pm 9.04$ & $328(6)$ & $61(1)^{\mathrm{b}}$ & $2.51 \pm 3.96^{\mathrm{b}}$ \\
\hline Open & 2,228 & $435(20)^{\mathrm{b}}$ & $11.83 \pm 13.29$ & $153(7)$ & $48(2)^{\mathrm{b}}$ & $3.82 \pm 6.84^{\mathrm{b}}$ \\
\hline
\end{tabular}

MIS minimally invasive surgery

${ }^{a}$ Rate refers to the number of complications within 30 days of procedure

b $P<0.05$, MIS vs open surgery 


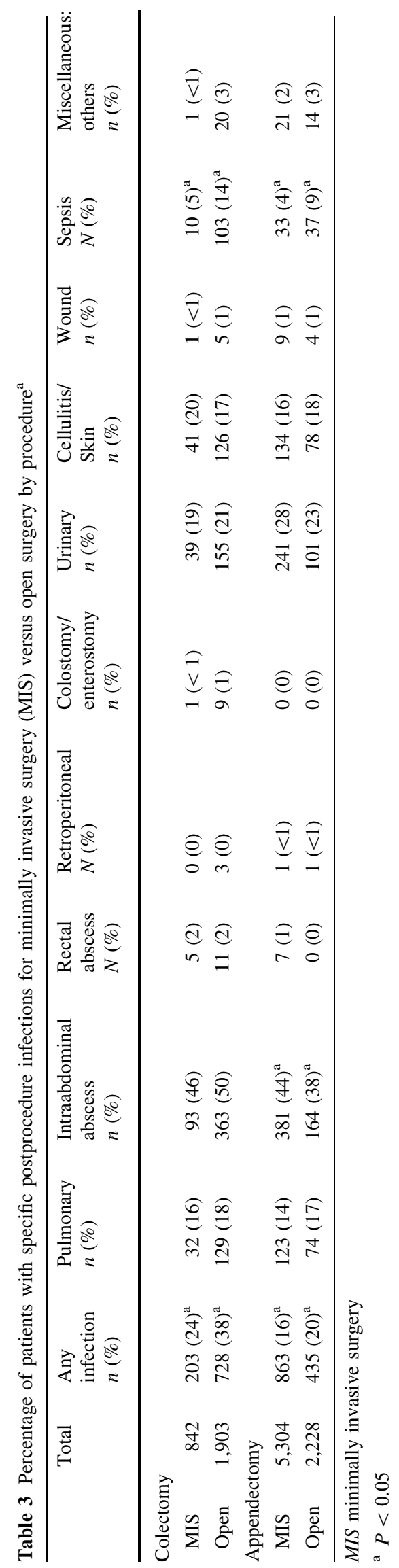

procedures, expenditures for episodes of care varied. Appendectomy procedures performed using an MIS route were associated with a lower adjusted cost for an episode of care than their open equivalents, with differences of approximately $\$ 700$.

\section{Colectomy}

The majority of colectomies were performed using open abdominal techniques (Table 1). Of the 2,745 patients who underwent colectomies, $842(31 \%)$ were treated using the MIS approach, whereas 1,903 (69\%) had open abdominal surgeries.

Considering the age strata, the distribution of use rates for MIS and open abdominal colectomy were similar. Within the 35- to 64-year age category (the age stratum including the majority of the colectomy procedures $[n=2,111,77 \%]$ ), MIS colectomy was used for 648 patients (31\%) and open abdominal colectomy for 1,463 patients $(69 \%)$. Within the stratum of patients 65 years old or older, 505 procedures were performed, with MIS colectomy accounting for 152 of the procedures (30\%) and open abdominal colectomies accounting for 353 procedures $(70 \%)$.

Patients undergoing open colectomies experienced more infections postoperatively (Table 2). However, these statistically significant differences in infection rates between MIS and open surgery $(P<0.05)$ were not reflected in days of antibiotics use. Incidences of minor and major bleeds were significantly more common after open colectomy procedures $(P<0.05)$. Procedure-specific complications, similar to those observed for appendectomies, (Table 3), were more common for colectomy patients undergoing open surgery, with statistically significant differences $(P<0.05)$. Intraabdominal, pulmonary, urinary, and skin infections were the most frequent types of postcolectomy infections for both MIS and open procedures. Infections were more frequent with open than with MIS procedures, and this difference was statistically significant $(P<0.05)$.

The predicted length of hospital stay (Table 4), adjusted for surgical approach, patient age, baseline CCI, geographic region, physician specialty, and procedure locale, was 4 days longer on the average for patients undergoing open colectomy than for those treated with MIS $(P<0.05)$. There was little difference in readmission rates between MIS and open colectomies.

Duration of care (Table 5) and costs for episode of care varied significantly for colectomy. Colectomy procedures performed through an MIS approach were associated with $\$ 15,200$ lower adjusted expenditures than their open equivalents $(P<0.05)$. Overall clinical and economic outcomes are summarized in Table 6. 
Table 4 Generalized linear modeling (GLM) estimates for index length of stay and unadjusted number of readmission/admission for minimally invasive surgery (MIS) versus open surgery by procedure

\begin{tabular}{|c|c|c|c|c|c|c|}
\hline & \multirow{2}{*}{$\begin{array}{l}\text { Total } \\
n\end{array}$} & \multirow{2}{*}{$\begin{array}{l}\text { LOS (days) }{ }^{\mathrm{a}} \\
\text { Mean } \pm \mathrm{SE}^{\mathrm{b}}\end{array}$} & \multicolumn{4}{|c|}{ Mean no. of readmissions } \\
\hline & & & Day 30 & Day 60 & Day 90 & Day 180 \\
\hline Colectomy & 2,479 & & & & & \\
\hline MIS & & $6.46 \pm 0.17^{\mathrm{c}}$ & $1.07 \pm 0.26$ & $1.00 \pm 0.00^{\mathrm{c}}$ & $1.15 \pm 0.38$ & $1.00 \pm 0.00$ \\
\hline Open & & $10.66 \pm 0.25^{\mathrm{c}}$ & $1.10 \pm 0.33$ & $1.07 \pm 0.26^{\mathrm{c}}$ & $1.02 \pm 0.15$ & $1.05 \pm 0.22$ \\
\hline Appendectomy & 4,717 & & & & & \\
\hline MIS & & $3.27 \pm 0.04^{\mathrm{c}}$ & $1.09 \pm 0.29$ & $1.10 \pm 0.30$ & $1.10 \pm 0.00$ & $1.00 \pm 0.00$ \\
\hline Open & & $3.91 \pm 0.08^{c}$ & $1.07 \pm 0.25$ & $1.00 \pm 0.00$ & $1.08 \pm 0.28$ & $1.00 \pm 0.00$ \\
\hline
\end{tabular}

$S E$ standard error of the mean, MIS minimally invasive surgery

${ }^{\text {a }}$ Index length of stay

b Bootstrapped standard errors obtained using 200 bootstrap repetitions

c $P<0.05$, MIS vs. open surgery

Table 5 Duration and costs for procedure-related episode of care for minimally invasive surgery (MIS) versus open surgery by procedure (report of multivariable findings)

\begin{tabular}{|c|c|c|c|c|}
\hline & $\begin{array}{l}\text { Duration of care }{ }^{\mathrm{a}} \text { (days) } \\
\text { Mean } \pm \mathrm{SE}\end{array}$ & $\begin{array}{l}\text { Cost for episode } \\
\text { of care }(\$)^{b} \\
\text { Mean }\end{array}$ & $\begin{array}{l}\text { Adjusted cost for } \\
\text { episode of care }(\$)^{\mathrm{c}} \\
\text { Mean }\end{array}$ & $\begin{array}{l}\text { Difference in } \\
\text { means }(\$) \\
n(95 \% \mathrm{CI})\end{array}$ \\
\hline \multicolumn{5}{|c|}{ Colectomy } \\
\hline MIS & $117.64 \pm 2.73^{\mathrm{d}}$ & $27,031.37^{\mathrm{d}}$ & $29,278.4^{\mathrm{d}}$ & \multirow[t]{2}{*}{$15,181.37(11,295.85-19,066.89)^{\mathrm{e}}$} \\
\hline Open & $128.15 \pm 1.8^{\mathrm{d}}$ & $47,091.40^{\mathrm{d}}$ & $44,459.77^{\mathrm{d}}$ & \\
\hline \multicolumn{5}{|c|}{ Appendectomy } \\
\hline MIS & $72.66 \pm 1.08$ & $11,298.16^{\mathrm{d}}$ & $11,552.41^{\mathrm{d}}$ & \multirow[t]{2}{*}{$700.66(28.8-1,372.52)^{\mathrm{d}}$} \\
\hline Open & $74.82 \pm 1.62$ & $14,031.95^{\mathrm{d}}$ & $12,253.07^{\mathrm{d}}$ & \\
\hline
\end{tabular}

$S E$ standard error of the mean, $C I$ confidence interval; $M I S$, minimally invasive surgery

a Days from index date of the surgical procedure to the last related medical or pharmacy claim, bootstrapped estimation

b Total cost of all claims during the duration of the care interval

c Adjusted for surgery type, patient age at index date, gender, Charlson Comorbidity Index, geographic region, and medical degree specialty

${ }^{\mathrm{d}} P<0.05$, MIS vs. open surgery

e $p<0.001$, MIS vs. open surgery

\section{Discussion}

This analysis focused on clinical and economic outcomes as reflected in a real-world database associated with two commonly performed surgical procedures: appendectomy and colectomy. By stratifying these procedures according to surgical approach, significant variability in the use of minimally invasive techniques was discernable. Appendectomy was performed most commonly using MIS techniques, whereas open surgery was more frequently performed for colectomy. Furthermore, postoperative infections were more common for patients undergoing open procedures, as was the incidence of major bleeding.
Although these differences argue for an advantage of MIS over open surgery, they also must be analyzed within the context of the limitations associated with the design of this study. Given the retrospective nature of these analyses, it was not possible to control completely for patient characteristics that may correlate with outcome variables of interest. To address this challenge, a multivariable general linear model (GLM) that adjusted for observed variations in patient characteristics (patient age, CCI, geographic region, surgical approach, and physician specialty) was constructed.

Although multivariate analyses adjust for observed differences in patient characteristics, unobserved differences not included in this model may have biased the results. For 
Table 6 Summary of clinical and economic outcomes for minimally invasive surgery (MIS) versus open surgery by procedure

\begin{tabular}{|c|c|c|c|c|}
\hline & $\begin{array}{l}\text { Total no. } \\
\text { of patients } \\
N\end{array}$ & $\begin{array}{l}\text { Procedure-specific } \\
\text { complication rate } \\
(\%)\end{array}$ & $\begin{array}{l}\text { Length of } \\
\text { hospital stay } \\
\text { (days) }\end{array}$ & $\begin{array}{l}\text { Adjusted difference } \\
\text { in costs }{ }^{\mathrm{b}} \\
\text { (\$) }\end{array}$ \\
\hline \multicolumn{5}{|c|}{ Colectomy } \\
\hline MIS & 842 & $5.93^{\mathrm{c}}$ & $6.46^{\mathrm{c}}$ & M \\
\hline Open & 1,903 & $8.56^{\mathrm{c}}$ & $10.66^{\mathrm{c}}$ & $15,181.37$ more dollars \\
\hline \multicolumn{5}{|c|}{ Appendectomy } \\
\hline MIS & 5,304 & $2.51^{\mathrm{c}}$ & $3.27^{\mathrm{c}}$ & - \\
\hline Open & 2,228 & $3.82^{\mathrm{c}}$ & $3.91^{\mathrm{c}}$ & 700.66 more dollars ${ }^{\mathrm{d}}$ \\
\hline \multicolumn{5}{|c|}{$M I S$ minimally invasive surgery } \\
\hline \multicolumn{5}{|c|}{${ }^{a}$ Number of complications within 30 days of procedure } \\
\hline \multirow{2}{*}{\multicolumn{5}{|c|}{$\begin{array}{l}\text { b Adjusted for surgery type, patient age on index date, gender, Charlson Comorbidity Index, geographic region, and medical degree specialty } \\
\text { c } P<0.05 \text {, MIS vs open surgery }\end{array}$}} \\
\hline & & & & \\
\hline \multicolumn{5}{|c|}{${ }^{\mathrm{d}} P<0.001$, MIS vs open surgery } \\
\hline
\end{tabular}

example, surgeon skill and experience in performing MIS or open surgery affects safety and efficacy outcomes; however, it was not incorporated directly into our analysis. An attempt was made to adjust for it by differentiating between general, colorectal, and other surgeons.

There are also limitations in the measures of disease severity. We account for disease severity by modeling both the Charlson comorbidity index and procedure-related expenditures incurred before the index procedure. The latter in particular incorporates procedures and medical care related to diagnosing and managing of the patient before surgery. The weakness of this measure as a proxy is that it indirectly adjusts only for disease severity.

Another limitation of our study relates to the data source. Although claims data are valuable tools for evaluating health outcomes, utilization, and spending, they are collected in this database for payment purposes and not for research. The presence of a claim for a medication, for example, did not necessarily translate into its use. Furthermore, medications purchased over the counter did not appear in claims reports. Finally, coding inaccuracies may have biased the results, particularly if they occurred systematically.

Our findings are largely in agreement with those of previous studies comparing MIS with open abdominal procedures reported in the literature. One meta-analysis of several clinical trials evaluating colectomy concluded that patients managed with minimally invasive techniques were less likely to experience postoperative ileus or a wound infection [14]. A recently published Cochrane review of randomized controlled trials evaluating appendectomy found that patients treated with MIS techniques were less likely to experience an infection postoperatively. In addition, these patients were discharged from the hospital 1 day earlier than their open surgery counterparts [16].

\section{Conclusion}

The results of our study suggest that the MIS approach for appendectomy and colectomy has lower infection rates, fewer complications, and shorter hospitalizations than the open techniques. The economic benefits of MIS surgery also were documented in our study. Interestingly, the improved results with the MIS approach were realized in both urgent care and elective surgery regardless of the age or clinical health status of the patient. This supports the continued evolution of the MIS approach for surgical diseases of the abdomen, with clinical and economic data to support selecting the MIS approach first when appendectomy and colectomy are considered.

Disclaimer Ethicon Endo-Surgery, Inc. has no independent knowledge concerning the information contained in this article, and findings and conclusions expressed are those reached by the authors.

Open Access This article is distributed under the terms of the Creative Commons Attribution Noncommercial License which permits any noncommercial use, distribution, and reproduction in any medium, provided the original author(s) and source are credited.

\section{Appendix}

See Table 7. 
Table 7 Hemorrhage characteristics

\begin{tabular}{|c|c|}
\hline Hemorrhage type & Codes \\
\hline \multicolumn{2}{|l|}{ Minor hemorrhage/bleeding } \\
\hline Selected intraocular (eye) & ICD-9 364.41, 372.72 \\
\hline $\begin{array}{l}\text { Hemopericardium (bleeding around the heart) } \\
\text { and hemothorax (into the lung cavity) }\end{array}$ & ICD-9 423.0, 860.2, 860.3, 860.4, 860.5 \\
\hline Esophageal & ICD-9 456.0, 456.20, 530.7, 530.82 \\
\hline Unspecified hemorrhage & ICD-9 459.0 \\
\hline $\begin{array}{l}\text { Gastric/duodenal/peptic/gastrojejunal ulcer with } \\
\text { hemorrhage }\end{array}$ & $\begin{array}{l}\text { ICD-9 531.0x, 531.2x, 531.4x, 531.6x, 532.0x, 532.2x, 532.4x, 532.6x, 533.0x, 533.2x, } \\
\text { 533.4x, 533.6x, 534.0x, 534.2x, 534.4x }\end{array}$ \\
\hline Other upper gastrointestinal hemorrhage & ICD-9 535.01, 535.11, 535.21, 535.31, 535.41, 535.51, 535.61, 537.83, 537.84 \\
\hline Lower gastrointestinal hemorrhage & ICD-9 562.02, 562.03, 562.12, 562.13, 569.3, 569.85, 569.86 \\
\hline Unspecified gastrointestinal hemorrhage & ICD-9 578.x \\
\hline Hemoperitoneum (abdominal cavity) & ICD-9 568.81 \\
\hline Urinary tract hemorrhage & ICD-9 596.7 (hemorrhage into bladder wall), 599.7 (hematuria) \\
\hline Hemorrhage in pregnancy & $\begin{array}{l}\text { ICD-9 } 639.1 \text { (delayed or excessive hemorrhage after abortion or ectopic/molar } \\
\text { pregnancy), 640.8x, 640.9x, 641.1x, 641.3x, 641.8x, 641.9x, 666.0x, 666.1x, 666.2x }\end{array}$ \\
\hline Respiratory system & ICD-9 784.7, 784.8, 786.3 \\
\hline Other & ICD-9 719.1x, 998.11, 998.12 \\
\hline \multicolumn{2}{|l|}{ Major hemorrhage/bleeding } \\
\hline Intracranial hemorrhage & $\begin{array}{l}\text { ICD-9 430, 431, 432, 432.0, 432.1, 432.9, 852, 852.0, 852.00, 852.01, 852.02, 852.03, } \\
852.04,852.05,852.06,852.09,852.1,852.10,852.11,852.12,852.13,852.14,852.15 \text {, } \\
852.16,852.19,852.2,852.20,852.21,852.22,852.23,852.24,852.25,852.26,852.29, \\
852.3,852.30,852.31,852.32,852.33,852.34,852.35,852.36,852.39,852.4,852.40, \\
852.41,852.42,852.43,852.44,852.45,852.46,852.49,852.5,852.50,852.51,852.52, \\
852.53,852.54,852.55,852.56,852.59,853,853.0,853.00,853.01,853.02,853.03, \\
853.04,853.05,853.06,853.09,853.1,853.10,853.11,853.12,853.13,853.14,853.15, \\
853.16,853.19\end{array}$ \\
\hline Intraocular (eye)(selected) & ICD-9 360.43, 362.43, 362.81, 363.61, 363.62,379.23 \\
\hline \multicolumn{2}{|l|}{ Control of hemorrhage/bleeding } \\
\hline & $\begin{array}{l}\text { ICD-9 } 02.13,06.02,06.92,21.0 x, 28.7,34.03,34.09,38.8 x, 39.3 x, 39.41,39.98,42.33 \text {, } \\
\quad 42.91,44.4 x, 44.91,45.43,49.95,50.61,54.12,54.19,57.93,60.94,75.8,96.06,96.14 \\
96.19\end{array}$ \\
\hline & $\begin{array}{l}\text { СРT 30901-30906, 30915-30920, 31238, 32110, 32654, 42960-42962, 42970-42972, } \\
\text { 43227, 43255, 43400, 43460, 43501-43502, 43840, 44366, 44378, 44391, 45317, } \\
\text { 45334, 45382, 46614, 47350-47362, 49002, 52606, 57180, 59160 }\end{array}$ \\
\hline \multicolumn{2}{|l|}{ Blood transfusion } \\
\hline & $\begin{array}{l}\text { HCPCS P9010, P9011, P9016, P9021, P9022, P9038, P9039, P9040, P9051, P9054, } \\
\text { P9056, P9057, P9058 }\end{array}$ \\
\hline & ICD-9 99.03, 99.04 \\
\hline
\end{tabular}

ICD International Classification of Diseases, CPT American Medical Association's Current Procedural Terminology, HCPCS Healthcare Common Procedure Coding System

\section{References}

1. Wu J, Wechter ME, Nguyen TV, Visco AG (2008) Hysterectomy rates in the United States, 2003. Obstet Gynecol 110:1091-1095

2. Babalola E, Bharucha A, Schleck C, Gebhart J, Zinsmeister A, Melton L III (2007) Decreasing utilization of hysterectomy: a population-based study in Olmsted county, Minnesota, 19652002. Am J Obstet Gynecol 196:214-217

3. Johnson N, Barlow D, Lethaby A, Tavender E, Curr E, Garry R (2006) Surgical approach to hysterectomy for benign gynaecological disease. Cochrane Database Syst Rev 19:CD003677

4. Kingsnorth A, LeBlanc K (2003) Hernias: inguinal and incisional. Lancet 362:1561-1571
5. Hinder R, Filipi C, Wetscher G, Neary P, DeMeester T, Perdikis G (1994) Laparoscopic Nissen fundoplication is an effective treatment for gastroesophageal reflux disease. Ann Surg 220:472-481

6. Strate U, Emmermann A, Fibbe C, Layer P, Zornig C (2008) Laparoscopic fundoplication: Nissen versus Toupet two-year outcome of a prospective randomized study of 200 patients regarding preoperative esophageal motility. Surg Endosc 22: $21-30$

7. Nguyen N, Zainabadi K, Mavandadi S, Paya M, Stevens C, Root JEA (2004) Trends in utilization and outcomes of laparoscopic versus open appendectomy. Am J Surg 188:813-820

8. Larson G (2000) Ventral hernia repair by the laparoscopic approach. Surg Clin North Am 80:1329-1340 
9. Earle D, Seymour N, Fellinger E, Perez A (2006) Laparoscopic versus open incisional hernia repair: a single-institution analysis of hospital resource utilization for 884 consecutive cases. Surg Endosc 20:71-75

10. Delaney C, Chang E, Senagore A, Broder M (2008) Clinical outcomes and resource utilization associated with laproscopic and open colectomy using a large national database. Ann Surg 247:819-824

11. Steele S, Brown T, Rush R, Martin M (2008) Laparoscopic vs open colectomy for colon cancer: results from a large nationwide population-based analysis. J Gastrointest Surg 12:583-591

12. Memon M, Fitzgibbons R Jr (1998) Assessing risks, costs, and benefits of laparoscopic hernia repair. Annu Rev Med 49:95-109

13. Young-Fadok T, Radice E, Nelson H, Harmsen W (2000) Benefits of laparoscopic-assisted colectomy for colon polyps: a casematched series. Mayo Clin Proc 75:344-348

14. Schwenk W, Haase O, Neudecker J, Muller J (2005) Short-term benefits for laparoscopic colorectal resection. Cochrane Database Syst Rev 20:CD003145

15. Salminen P, Hiekkanen H, Rantala A, Ovaska J (2007) Comparison of long-term outcome of laparoscopic and conventional nissen fundoplication: a prospective randomized study with an 11-year follow-up. Ann Surg 246:201-206
16. Sauerland S, Lefering R, Neugebauer E (2004) Laparoscopic versus open surgery for suspected appendicitis. Cochrane Database Syst Rev CD001546

17. Keus F, de Jong J, Gooszen H, an Laarhoven C (2006) Laparoscopic versus open cholecystectomy for patients with symptomatic cholecystolithiasis. Cochrane Database Syst Rev CD006231

18. Kovac S (2004) Transvaginal hysterectomy: rationale and surgical approach. Obstet Gynecol 103:1321-1325

19. Charlson M, Pompei P, Ales K, McKenzie C (1987) A new method of classifying prognostic comorbidity in longitudinal studies: development and validation. J Chronic Dis 40:373-383

20. Deyo RA, Cherkin DC, Ciol MA (1992) Adapting a clinical comorbidity index for use with ICD-9-CM administrative databases. J Clin Epidemiol 45:613-619

21. Manning W, Mullahy J (2001) Estimating log models: to transform or not to transform? J Health Econ 20:461-494

22. Blough D, Madden C, Hornbrook M (1999) Modeling risk using generalized linear models. J Health Econ 18:153-171

23. Duan N (1983) Smearing estimate: a nonparametric retransformation method. J Am Stat Assoc 78:605-610

24. Efron B, Tibshirani R (1993) An introduction to the bootstrap. Chapman \& Hall/CRC, Boca Raton, FL 